treatment : it was lower on treatment $\mathrm{N}$ for daily gain on test $(24$ vs 27 p. 100), food conversion ratio ( 21 vs 26 p. 100) and backfat thickness (24 vs 29 p. 100). As the genetic portion of these variance components is expected to be similar in both treatments, it is suggested that the reduction in age at the entry into the station can result in some decrease in the environmental portion of the between-herd variance for traits recorded in central boar testing stations.

\title{
Analysis of boar buying policies in a commercial herd
}

\author{
L. OLLIVIER *, J.W. JAMES ** \\ *I.N.R.A., Station de Génétique Quantitative et Appliquée, 78350 Jouy-en-Josas \\ **k School of Wool and Pastoral Sciences, The University of New South Wales, \\ Kensington, N.S.W., 2033 (Australie)
}

The results of a previous theoretical study (James J.W., 1980. Ann. Génét. Sél. anim., 12, 33-47) are here applied to the case of boar purchases in a commercial herd. An expression is derived for the net present value of a boar from the expected gains in productivity of its progeny, as a function of purchase price and relative breeding value. But the producer must also consider the genetic gains made by the breeding nucleus providing him with boars. This leads to define an optimum length of time for which a boar should be used, which depends on price, breeding value, and rate of genetic gain in the nucleus. It is also shown that net present value and optimum length of use depend on the crossbreeding system which the boar enters as well as the way in which it is used, i.e. artificial insemination (A.I.) or natural service. A numerical application is provided by the boars auctioned from French performance test stations (C.I.). Very highly significant relationships between boar price and breeding value (estimated by the selection index) have been established, for each category of buyers, on 4566 boards sold in 1981-1983 at those stations. The price paid by producers and A.I. centers may be approximated by a linear function of the index, whereas a curved relation is obtained for breeders. On the basis of those relationships, the buying of C.I. boars by a producer appears to be a very profitable operation, the overall annual benefit being around 2.3 millions F.F. for the French producers using such boars. Boars used in A.I. contribute to nearly 75 percent of that global profit, as a result of their high genetic value as well as of the diffusion allowed by the reproduction technique. With the observed price function, the best policy for the producer is to buy the best available sires. Furthermore, a quick renewal is economically justified for A.I. boars. These should indeed be used, for the best of them, less than one year.

\section{A note on genetic parameters of on-the-farm control in France (1981-1984)}

\author{
R. GUEBLEZ *, P. SELLIER ** \\ * I.T.P., Service Sélection, B.P. 3, 35650 Le Rheu \\ **I.N.R.A., Station de Génétique Quantitative et Appliquée, 78350 Jouy-en-Josas
}

This analysis deals with performance records collected in the years 1981-1984 in 104 breeding farms participating in the French on-farm testing programme. Data were obtained from 142,218 purebred gilts or boars from Large White (LW) or French Landrace (FL) breed. Traits are age (AGE) and ultrasonic backfat thickness (BT) at $10 \mathrm{~kg}$ live weight. Deviations from batch average were used for analysis, the batch being a group of about 30 contemporary pigs from the same herd-breed-sex combination and born within the same 